Research Article

\title{
Determination of Weak Knock Characteristics for Two-Stroke Spark Ignition UAV Engines Based on Mallat Decomposition Algorithm
}

\author{
Jing Sheng $\mathbb{D}^{1}{ }^{1}$ Yuping Zeng, ${ }^{1}$ Guoman Liu, ${ }^{1}$ and Rui Liu $\mathbb{D}^{2}$ \\ ${ }^{1}$ Jiangxi Province Key Laboratory of Precision Drive \& Control, Nanchang Institute of Technology, Nanchang 330099, China \\ ${ }^{2}$ School of Mechanical and Power Engineering, Nanjing Tech University, Nanjing 211816, China \\ Correspondence should be addressed to Jing Sheng; jing.sheng@nit.edu.cn and Rui Liu; timliu@njtech.edu.cn
}

Received 16 August 2020; Revised 24 January 2021; Accepted 6 February 2021; Published 20 February 2021

Academic Editor: Emiliano Mucchi

Copyright (c) 2021 Jing Sheng et al. This is an open access article distributed under the Creative Commons Attribution License, which permits unrestricted use, distribution, and reproduction in any medium, provided the original work is properly cited.

\begin{abstract}
Two-stroke spark ignition (SI) unmanned aerial vehicle (UAV) engines do not allow heavy knock and require a certain knock safety margin. However, weak knock can help the engine increase power output and reduce fuel consumption. To accurately extract the knock characteristics of engine vibration signals under the condition of weak knock, a signal feature extraction method based on the Mallat decomposition algorithm was proposed. Mallat decomposition algorithm can decompose the signal into two parts: a low-frequency signal and a high-frequency noise signal. The decomposed high-frequency noise is eliminated, and the lowfrequency signal is retained as the characteristic domain signal. Simulation results show the effectiveness of the proposed algorithm. The engine vibration signal of a two-stroke SI UAV engine was decomposed into the low-frequency signal and the highfrequency signal by the Mallat decomposition algorithm. The low-frequency signal is taken as the knock characteristic domain signal component, and the wavelet packet energy method is used to verify the correctness of the obtained signal component. The relative energy parameter is calculated by using the knock characteristic domain signal component, which can be used as the determination index of knock intensity. This method provides a reference for the weak knock control of two-stroke SI UAV engines.
\end{abstract}

\section{Introduction}

Fuel-powered UAVs have been widely applied in agricultural, forestry, plant operations, and military due to their simple structure, easy control, steady running, and landform independence [1]. Two-stroke SI engines are widely used in the field of UAVs because of the advantages of high specific power, simple structure, small size, low manufacturing cost, and easy maintenance [2].

For SI engines, knock is a characteristic abnormal combustion phenomenon. In the heavy knock study using highspeed photography, it was found that the unburned mixture away from the spark plug would be compressed due to the expansion of the burning mixture during the flame propagation. As a result, due to the action of thermal radiation, the local temperature exceeds the spontaneous combustion temperature of the fuel, which causes the spontaneous combustion reaction to occur, thus forming one or more flame cores. Flame propagation speed exceeds $200-1000 \mathrm{~m} / \mathrm{s}$. The pressure shock waves generated by high-speed knock combustion in the cylinder reflect and repeatedly impact the cylinder wall, causing forced vibration and high-frequency noise. The impact of pressure wave thins the air film and increases the heat loss to the cylinder wall. As a result, power decreases, fuel consumption increases, the engine block overheats, and the temperature of the cooling water and oil rises. Heavy knock will damage the oil film on the cylinder wall, aggravate the wear of the cylinder wall, and even damage the parts $[3,4]$. Two-stroke SI UAV engines are not allowed to have the heavy knock and need to set a certain knock safety margin. Therefore, heavy knock has become one of the major obstacles to the development of two-stroke SI UAV engines. 
When the SI engine works in the weak knock state, the combustion process is close to the constant volume process, and the engine's power and economy are improved [5]. Therefore, knock control aims to make the engine work in the weak knock state. And the accurate detection and identification of knock state is the precondition of knock control for two-stroke SI UAV engines. At present, the main method to detect knock is to measure cylinder pressure or engine vibration.

In the process of knock, pressure waves bounce back and forth within the combustion boundary at the speed of sound and thus oscillate in the combustion chamber [6]. Finally, the oscillation is transmitted to the combustion chamber wall, causing the engine cylinder to vibrate at a certain frequency. Measuring cylinder pressure signal with a cylinder pressure sensor is the most direct monitoring method of knock state, which can accurately and sensitively identify engine knock. However, cylinder pressure sensors are very expensive and not suitable for practical engineering applications.

The indirect knock detection method uses the vibration acceleration sensor to measure the response of the engine body under knock excitation and processes the measured vibration signals to highlight the knock characteristics. Compared with the direct method, this detection method does not need to invade the cylinder and does not affect the combustion. The vibration acceleration sensor is easy to install and does not need to modify the engine structure. The sensor has a long life and is relatively cheap. Therefore, this method has become a research hotspot [7].

However, the disadvantage of the indirect method is also obvious. There is a lot of noise interference in the engine vibration signals collected by the vibration acceleration sensor because these signals come from the superposition of multiple excitations. These noises will interfere with the engine knock detection process and affect the accuracy of the results, especially for weak knock conditions. Because the knock excitation signal is weak in energy, it is easy to be covered by the noise signal, resulting in errors in the detection process. Therefore, how to improve the signal-tonoise ratio (SNR) and reduce the influence of noise signal on the detection accuracy is the first problem to be solved when using engine vibration signals for knock detection. Therefore, it is of great significance in engineering to effectively utilize the signal processing method and analyze engine vibration signals to distinguish the knock state, especially the weak knock state [8-12].

Signal transform technology is a useful tool for knock feature extraction methods, such as short-time Fourier transform (STFT [13]), Wigner-Ville distribution (WVD [14]), and wavelet transform [15-17], which have been applied to analyze engine vibration signals for knock detection in the past decades.

Considering the resonance vibration of the engine caused by knock shock, the vibration signal obtained has the characteristics of nonstationary and nonlinear in nature. STFT and WVD can process nonstationary signals. However, the computational intensity of their time-frequency representation in two-dimensional space limits their implementation in real-time applications. Wavelet transform is a popular time-frequency analysis tool. It is widely concerned with the extraction of transient features from complex signal backgrounds and the identification of mechanical faults at the initial stage.

In recent years, wavelet transform has been widely used in knock feature extraction due to its multiresolution characteristics and its ability to represent local features of signals in both time and frequency domains $[18,19]$. Mallat algorithm is a fast algorithm for decomposition and reconstruction of the wavelet transform, which is based on the theory of multiresolution analysis. Mallat algorithm is as important in wavelet transform as FFT is in Fourier transform. It can greatly reduce the computation of wavelet transform and is beneficial to the processing of nonstationary signals with low SNR. By selecting the appropriate decomposition coefficient, more useful signal information can be retained, noise component can be reduced, and timefrequency resolution can be effectively improved [20]. Mallat algorithm includes Mallat decomposition algorithm and Mallat reconstruction algorithm.

In this paper, the Mallat decomposition algorithm is used to separate the engine vibration signals of the twostroke SI UAV engine, and the knock characteristic domain signal component is extracted effectively. This component can be used to calculate the relative energy parameter as an index to evaluate the knock intensity, which lays a foundation for knock identification.

\section{Method}

Since the scale and time migration of the wavelet transform is continuous, it is necessary to discretize the decomposition scale and migration of wavelet transform for the convenience of software implementation and engineering application. To reduce the amount of computation, Mallat decomposition algorithm is adopted in this paper to separate the vibration signals of the two-stroke SI UAV engine, and the signal components in the weak knock characteristic domain are obtained.

The multiresolution analysis (MRA) was proposed by Stéphane Mallat and Yves Meyer. MRA not only provides a simple method for constructing orthogonal wavelet basis but also provides a theoretical basis for Mallat algorithm, a fast algorithm for orthogonal wavelet transform. Mallat decomposition algorithm can decompose signals at multiple levels. Its basic principle is that the decomposed high-frequency signal components are convolved with the wavelet coefficients and the high-pass filter, and the remaining lowfrequency signal components are transmitted to the next horizontal similar decomposition. The basic idea of the Mallat decomposition algorithm is as follows.

It is assumed that the signal $f(t)$ is the engine vibration signal under the weak knock state to be processed. The signal $f(t) \in L^{2}(R)$ under resolution $2^{j}$ is decomposed into $A_{j} f(t)$ and $D_{j} f(t)$, where $j$ is the number of decomposition layers. The discrete approximation of $f(t)$ under resolution $2^{j}$ to $A_{j} f(t)$ is the wavelet coefficient of the low-frequency part of the engine vibration signal. The detailed part of $f(t)$ 
under resolution $2^{j}$ to $D_{j} f(t)$ is the wavelet coefficient of the engine vibration signal in the high-frequency part of layer $j$. The discrete approximation of $f(t)$ under resolution $2^{j-1}$ to $A_{j-1} f(t)$ can be obtained by filtering $A_{j} f(t)$ with a discrete low-pass filter $H$. The detailed part of $f(t)$ under resolution $2^{j-1}$ to $D_{j-1} f(t)$ can be obtained by filtering $D_{j} f(t)$ with discrete high-pass filter $G$. After removing the high-frequency coefficient of layer $j$ decomposed from $f(t)$, the lowfrequency coefficient is retained. Mallat decomposition algorithm is used to reconstruct the low-frequency coefficients to obtain the characteristic signal components containing weak knock information.

When the scale function $\varnothing(t)$ of multiresolution analysis is determined, the wavelet function $\varphi(t)$ can be constructed. If the scaling function is orthogonal, the multiresolution analysis is orthogonal multiresolution. Then, the discrete approximation $A_{j} f(t)$ and the detailed part $D_{j} f(t)$ can be expressed as [21]

$$
\begin{aligned}
& A_{j} f(t)=\sum_{-\infty}^{\infty} c_{j, k} \cdot \varnothing_{j, k}(t), \\
& D_{j} f(t)=\sum_{-\infty}^{\infty} d_{j, k} \cdot \varphi_{j, k}(t) .
\end{aligned}
$$

In equations (1) and (2), $c_{j, k}$ and $d_{j, k}$ are rough coefficient and detail coefficient under $2^{j}$ resolution, respectively.

According to the decomposition principle of the Mallat decomposition algorithm, $A_{j} f(t)$ is decomposed into the sum of rough coefficient $A_{j-1} f(t)$ and detail coefficient $D_{j-1} f(t)$, that is,

$$
\begin{aligned}
A_{j} f(t) & =A_{j-1} f(t)+D_{j-1} f(t) \\
A_{j-1} f(t) & =\sum_{m=-\infty}^{\infty} c_{j-1, m} \cdot \varnothing_{j-1, m}(t) \\
D_{j-1} f(t) & =\sum_{m=-\infty}^{\infty} d_{j-1, m} \cdot \varphi_{j-1, m}(t) \\
\sum_{m=-\infty}^{\infty} c_{j-1, m} & \cdot \varnothing_{j-1, m}(t)+\sum_{m=-\infty}^{\infty} d_{j-1, m} \cdot \varphi_{j-1, m}(t) \\
& =\sum_{m=-\infty}^{\infty} c_{j, m} \cdot \varnothing_{j, m}(t)
\end{aligned}
$$

According to the biscale equation of scale function, the following equation can be obtained:

$$
\begin{aligned}
\varnothing_{j-1, k}(t) & =2^{j-1 / 2} \cdot \varnothing\left(2^{j-1} t-k\right) \\
& =2^{j-1 / 2} \cdot \sqrt{2} \sum_{i=-\infty}^{\infty} h(i) \cdot \varnothing\left(2^{j} t-2 k-i\right) .
\end{aligned}
$$
as

By substituting $m^{\prime}=2 k+i$, equation (7) can be written

$$
\begin{aligned}
\varnothing_{j-1, k}(t) & =\sum_{m^{\prime}=-\infty}^{\infty} h\left(m^{\prime}-2 k\right) \cdot 2^{j / 2} \cdot \varnothing\left(2^{j} t-m^{\prime}\right) \\
& =\sum_{m^{\prime}=-\infty}^{\infty} h\left(m^{\prime}-2 k\right) \cdot \varnothing_{j, m^{\prime}}(t) .
\end{aligned}
$$

According to the orthonormal property of $\varnothing_{j, k}(t)$, the inner product of both sides with $\varnothing_{j, m}(t)$ can be obtained:

$$
\left\langle\varnothing_{j-1, k}, \varnothing_{j, m}\right\rangle=h(m-2 k) \text {. }
$$

Take the complex conjugate to get

$$
\left\langle\varnothing_{j, m}, \varnothing_{j-1, k}\right\rangle=h^{*}(m-2 k) \text {. }
$$

Similarly, from the two-scale equation of the wavelet function, the following equation can be obtained:

$$
\begin{aligned}
\varphi_{j-1, k}(t) & =2^{(j-1) / 2} \cdot \varphi\left(2^{j-1} t-k\right) \\
& =\sum_{m^{\prime}=-\infty}^{\infty} \mathrm{g}\left(m^{\prime}-2 k\right) \cdot \varphi_{j, m^{\prime}}(t) .
\end{aligned}
$$

The inner product of both sides of equation (11) with $\varnothing_{j, m}(t)$ is

$$
\left\langle\varphi_{j-1, k}, \varnothing_{j, m}\right\rangle=\mathrm{g}(m-2 k) .
$$

Take the complex conjugate to get

$$
\left\langle\varnothing_{j, m}, \varphi_{j-1, k}\right\rangle=\mathrm{g}^{*}(m-2 k) \text {. }
$$

Take the inner product of both sides of equation (6) with the relevant function. According to orthogonality, the following important conclusions can be drawn:

(1) Take the inner product with $\varnothing_{j-1, k}(t)$ on both sides of equation (6) and combine it with equation (10) to get

$$
C_{j-1, k}(t)=\sum_{m^{\prime}=-\infty}^{\infty} h^{*}(m-2 k) \cdot C_{j, m} .
$$

(2) Take the inner product with $\varnothing_{j-1, k}(t)$ on both sides of equation (6) and combine with equation (13) to obtain

$$
d_{j-1, k}(t)=\sum_{m^{\prime}=-\infty}^{\infty} \mathrm{g}^{*}(m-2 k) \cdot C_{j, m} .
$$

(3) Take the inner product with $\varnothing_{j, k}(t)$ on both sides of equation (6) and combine with equations (10) and (13) to obtain

$$
C_{j, k}=\sum_{m=-\infty}^{\infty} h(k-2 m) C_{j-1, m}+\sum_{m=-\infty}^{\infty} \mathrm{g}(k-2 m) d_{j-1, m} .
$$

Define the infinite dimensional vectors $c_{j}=\left[c_{j, k}\right]_{k=-\infty}^{\infty}$ and $d_{j}=\left[d_{j, k}\right]_{k=-\infty}^{\infty}$. Define the matrix $H=\left[H_{m, k}\right]_{m, k=-\infty}^{\infty}$ and $G=\left[G_{m, k}\right]_{m, k=-\infty}^{\infty}$, where $H_{m, k}=h^{*}(m-2 k)$ and 
$G_{m, k}=\mathrm{g}^{*}(m-2 k)$. Then, equations $(14)-(16)$ can be abbreviated as

$$
\left\{\begin{array}{l}
c_{j-1}=H c_{j}, \\
d_{j-1}=G c_{j} .
\end{array}\right.
$$

In equation (17), $j=0,1, \ldots, J$.

\section{Simulation Experiment}

To verify the effectiveness of the Mallat decomposition algorithm in extracting characteristic domain signals, a simulation experiment is designed. In the simulation experiment, Mallat decomposition algorithm decomposed a simulation signal $S(t)$ into two layers. The simulation signal $S(t)$ is composed of a source signal $k(t)$ and noise signal $N$. To intuitively analyze the decomposition results of the Mallat decomposition algorithm, the source signal $k(t)$ used in this paper is a sinusoidal signal.

$$
S(t)=k(t)+N=4 \sin (2 \pi f t)+N .
$$

In equation (18), frequency $f$ is $20 \mathrm{~Hz}$ and the sampling frequency is $2000 \mathrm{~Hz}$. The time-domain diagram of the simulation signal component $k(t)$ is shown in Figure 1 .

$k(t)$ is the sinusoidal signal with amplitude 4 . Add the noise signal $N$ to the simulation signal component $k(t)$ to obtain the simulation signal $S(t)$. The noise signal $N$ is a normally distributed white noise, which has a mean of 0 and a variance of 0.4 . The time-domain diagram of the noise signal $N$ is shown in Figure 2. The time-domain diagram of the simulation signal $S(t)$ is shown in Figure 3.

Mallat decomposition algorithm was used for the twolayer decomposition of the simulated signal $S(t)$. The wavelet function $d b 2$ was used to decompose the simulated signal $S(t)$, and the effective component $k^{\prime}(t)$ and the noise component $N^{\prime}$ were obtained, respectively. The time-domain diagram of the effective component $k^{\prime}(t)$ is shown in Figure 4 . The time-domain diagram of the noise component $N^{\prime}$ is shown in Figure 5.

As can be seen from Figures 4 and 5, Mallat decomposition algorithm can decompose the simulated signal $S(t)$ to obtain two signal components, namely, the low-frequency component $k^{\prime}(t)$ and the high-frequency component $N^{\prime}$, among which the low-frequency component $k^{\prime}(t)$ is the sinusoidal signal. The magnitude of $N^{\prime}$ is between -0.2 and 0.2 , which is consistent with the noise signal $N$. The magnitude of $k^{\prime}(t)$ is increased. The low-frequency component $k^{\prime}(t)$ is processed with FFT to obtain its frequency-domain diagram, as shown in Figure 6. As shown in Figure 6, the frequency of the separated sinusoidal signal is $20 \mathrm{~Hz}$, consistent with that of the source signal.

The simulation results show that Mallat decomposition algorithm can be used to separate the simulation signal, which can filter out most of the noise components and get the characteristic signal components effectively.

\section{Experiment Setup}

4.1. Test Engine. In this paper, an experimental study of a two-cylinder two-stroke SI piston engine has been carried out. The main structure of the engine includes the intake system, the fuel supply system, and the electronic control system. Table 1 shows the test engine specifications.

4.2. Test Bench. The engine test bench layout and test bench image are shown in Figures 7 and 8, respectively. An acceleration sensor is used to collect engine vibration signals, and a spark plug cylinder pressure sensor is used to collect cylinder pressure signals. During the experiment, cylinder pressure signals and engine vibration signals are recorded by a high-speed data acquisition instrument. The sampling frequency is set to $200 \mathrm{kHz}$ to maintain the high-frequency characteristics of signals.

\section{Analysis of Test Results}

The peak value of the cylinder pressure signal curve increases with the increase of knock intensity and is accompanied by obvious high-frequency oscillation. Therefore, the highfrequency oscillation can indicate the knock intensity $[22,23]$. Figure 9 shows the cylinder pressure signals obtained by the cylinder pressure sensor when the engine has heavy knock or nonknock. Figure 9(a) shows the cylinder pressure signal obtained under the condition of heavy knock, and Figure 9(b) shows the cylinder pressure signal obtained under the condition of nonknock. In this paper, the high-frequency oscillation of the engine cylinder pressure signal is used to judge the knock intensity of the engine vibration signal. Therefore, cylinder pressure signals and engine vibration signals are collected synchronously.

The engine speed is $5000 \mathrm{rpm}$, and the inlet air temperature is $301 \mathrm{~K}$ when cylinder pressure signals and engine vibration signals are collected. A self-developed electronic control unit (ECU) is used to control the engine working parameters such as fuel injection pulse width, fuel injection timing angle, and ignition timing angle freely. The ignition timing angle is controlled to change the state of knock.

\subsection{The Result of One Engine Working Cycle of $25^{\circ} \mathrm{CA}$ Ignition} Advance Angle. Figure 10 shows the cylinder pressure signal and the engine vibration signal collected synchronously during a working cycle when the ignition advance angle of the test engine is $25^{\circ} \mathrm{CA}$. In Figure $10(\mathrm{a})$, the intensity of high-frequency pressure oscillations is between nonknock and heavy knock, so it can be determined that the engine vibration signal in Figure 10(b) is the signal collected at the state of weak knock.

Mallat decomposition algorithm was used to separate the engine vibration signal shown in Figure 10(b). The two-layer decomposition of the signal is performed by using the wavelet function $d b 2$. The engine vibration signal is 


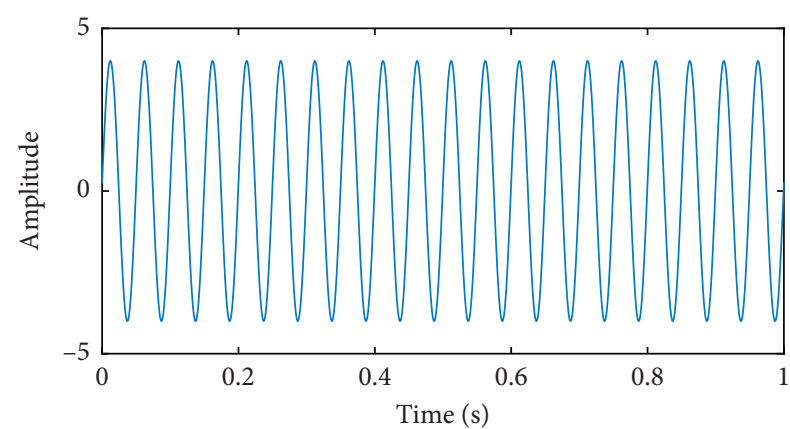

Figure 1: The time-domain diagram of the source signal $k(t)$.

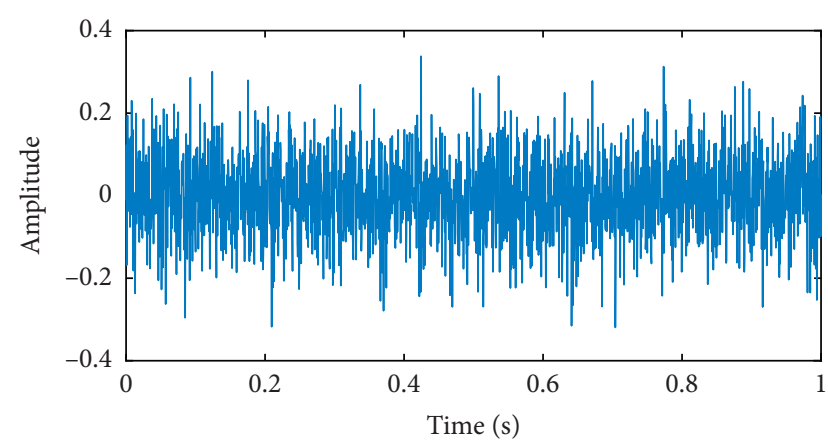

Figure 2: The time-domain diagram of the noise signal $N$.

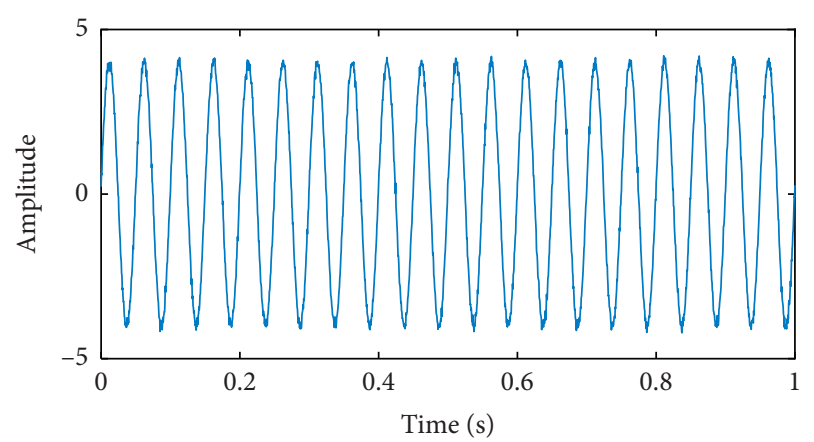

Figure 3: The time-domain diagram of the simulation signal $S(t)$.

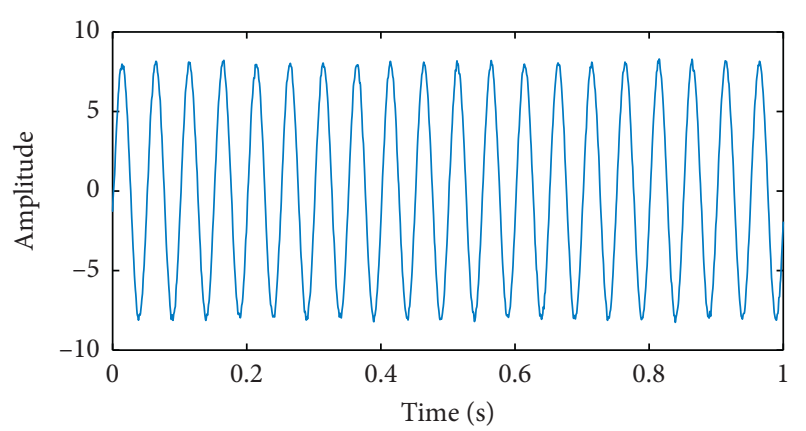

Figure 4: The time-domain diagram of the low-frequency component $k^{\prime}(t)$.

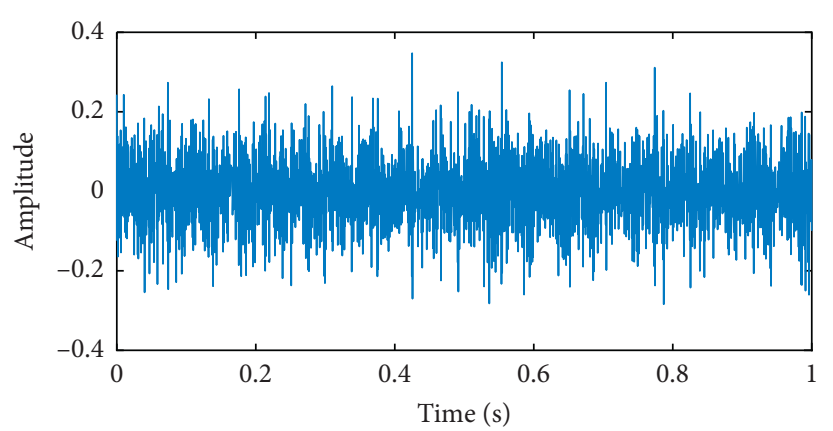

Figure 5: The time-domain diagram of the high-frequency component $N^{\prime}$.

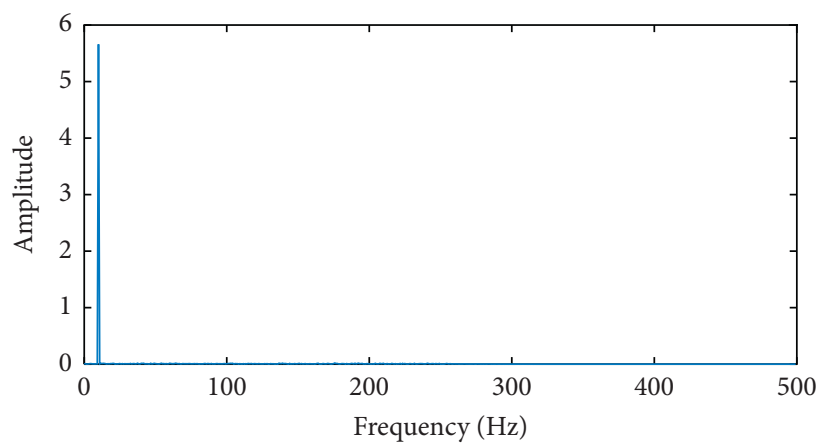

Figure 6: The frequency-domain diagram of $k^{\prime}(t)$.

TABle 1: Specifications of the test engine.

\begin{tabular}{lc}
\hline Items & Value \\
\hline Engine type & Two-stroke SI engine \\
Intake style & Reed valve \\
Stroke $(\mathrm{mm})$ & 69 \\
Bore $(\mathrm{mm})$ & 76 \\
Displace $\left(\mathrm{cm}^{3}\right)$ & 625 \\
Geometric compression ratio & 9.5 \\
Exhaust port opening (CA ATDC) & 88 \\
Scavenging port opening (CA ATDC) & 122 \\
\hline
\end{tabular}

decomposed into the low-frequency signal component and the high-frequency noise signal component, as shown in Figures 11 and 12, respectively. As can be seen from Figure 11, the amplitude of the low-frequency signal component increases, and some noise in the engine vibration signal is reduced.

FFT is used to process the low-frequency signal components, and the frequency-domain figure obtained is shown in Figure 13.

In Figure 13, the characteristic frequency of weak knock in one working cycle is $3027 \mathrm{~Hz}$ when the ignition advance angle is $25^{\circ} \mathrm{CA}$ at $5000 \mathrm{rpm}$.

\subsection{The Result of One Engine Working Cycle of $27^{\circ} \mathrm{CA}$ Ignition} Advance Angle. At $5000 \mathrm{rpm}$, when the ignition advance angle is $27^{\circ} \mathrm{CA}$, the cylinder pressure signal and the engine vibration signal of one working cycle are obtained 


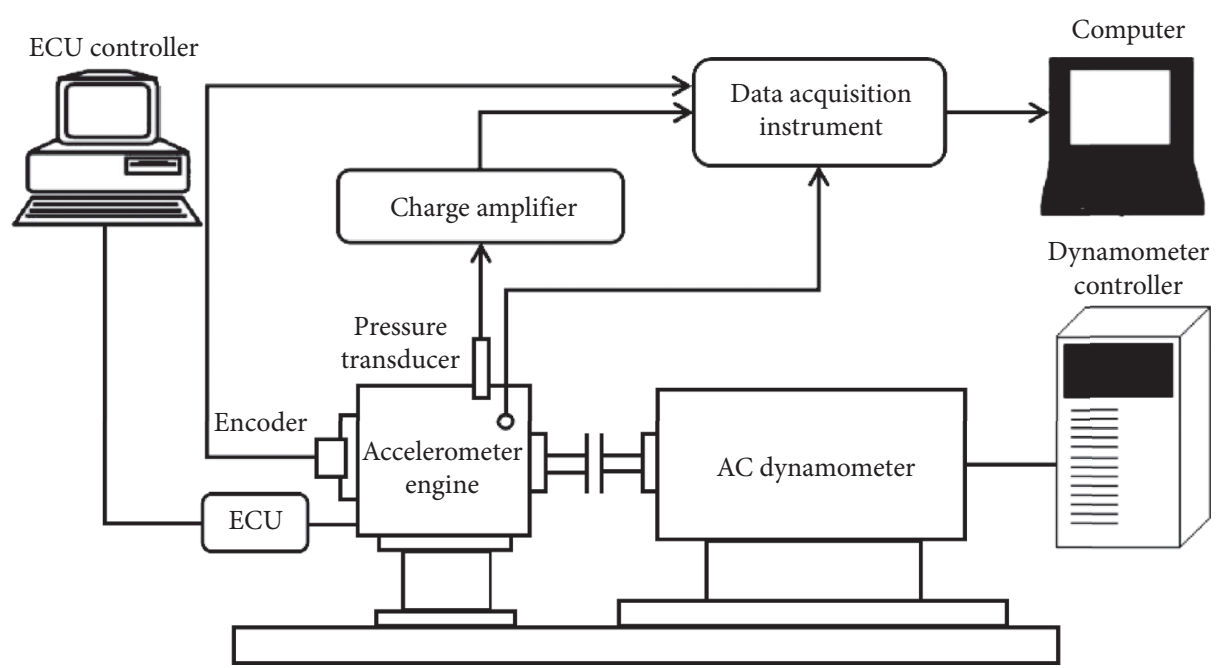

Figure 7: Schematic diagram of the engine test bench.

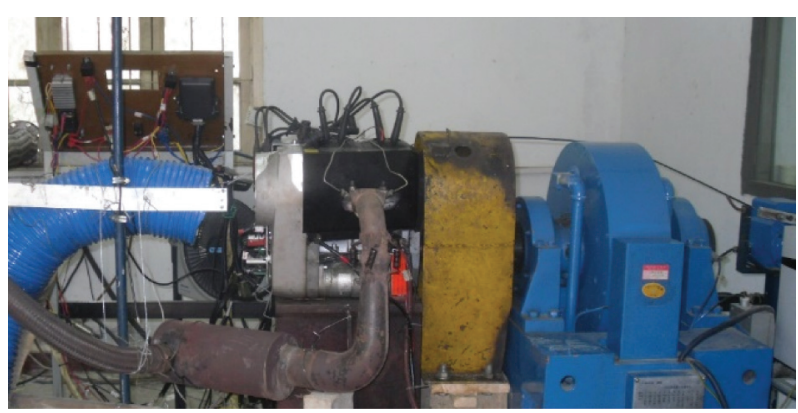

FIGURE 8: Image of the engine test bench.

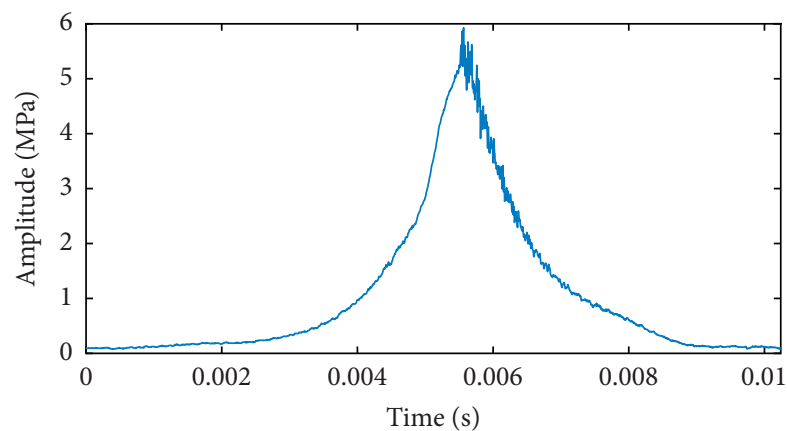

(a)

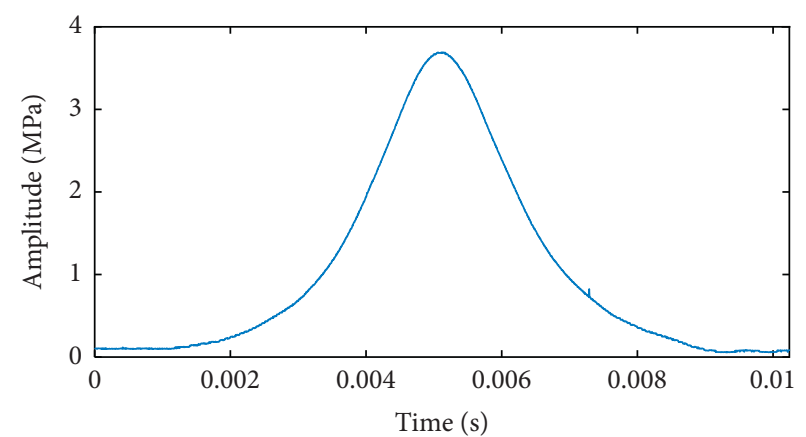

(b)

Figure 9: The cylinder pressure signal curve of (a) heavy knock and (b) nonknock.

synchronously, as shown in Figures 14(a) and 14(b), respectively. According to the high-frequency oscillation of the cylinder pressure signal in Figure 14(a), it can be seen that the cylinder pressure signal is in the state of weak knock. Therefore, it can be concluded that the engine vibration signal in Figure 14(b) is in the state of weak knock.
Mallat decomposition algorithm is used to decompose the engine vibration signal shown in Figure 14(b) into two layers, where the wavelet function is $d b 2$. The low-frequency signal component and the high-frequency noise signal component are obtained, as shown in Figures 15 and 16, respectively. 


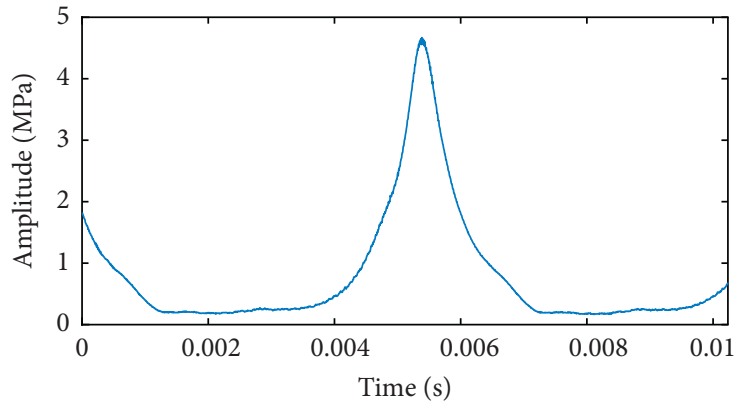

(a)

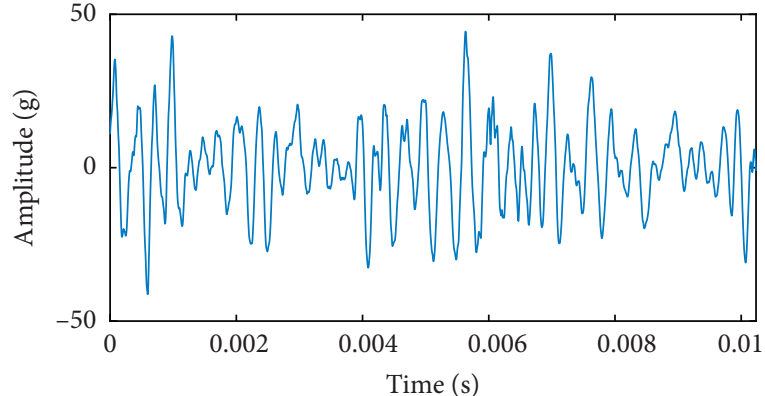

(b)

Figure 10: Time-domain diagram of the cylinder pressure signal and the engine vibration signal collected synchronously at $5000 \mathrm{rpm}$ when the ignition advance angle is $25^{\circ} \mathrm{CA}$. (a) The time-domain diagram of the cylinder pressure signal. (b) The time-domain diagram of the engine vibration signal.

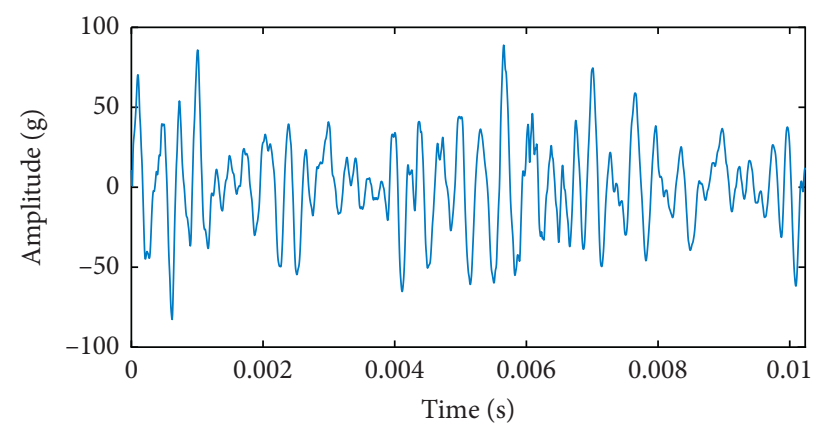

Figure 11: Time-domain diagram of the low-frequency signal component at $5000 \mathrm{rpm}$ when the ignition advance angle is $25^{\circ} \mathrm{CA}$.

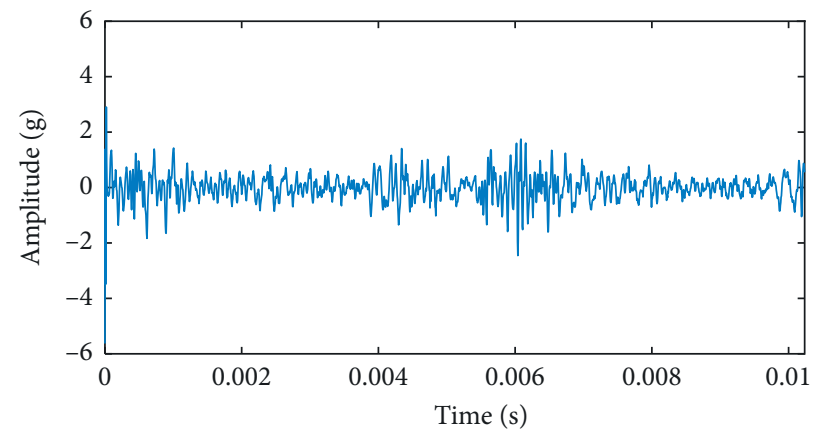

Figure 12: Time-domain diagram of the high-frequency noise signal component at $5000 \mathrm{rpm}$ when the ignition advance angle is $25^{\circ} \mathrm{CA}$.

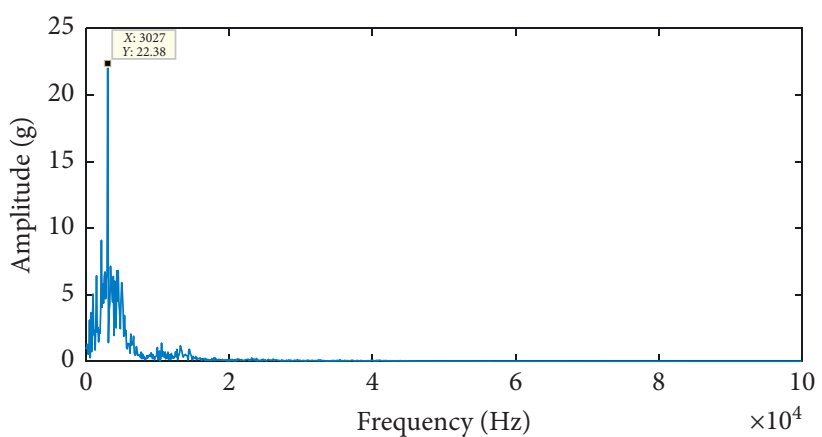

Figure 13: Frequency-domain diagram of the low-frequency signal component at $5000 \mathrm{rpm}$ when the ignition advance angle is $25^{\circ} \mathrm{CA}$. 


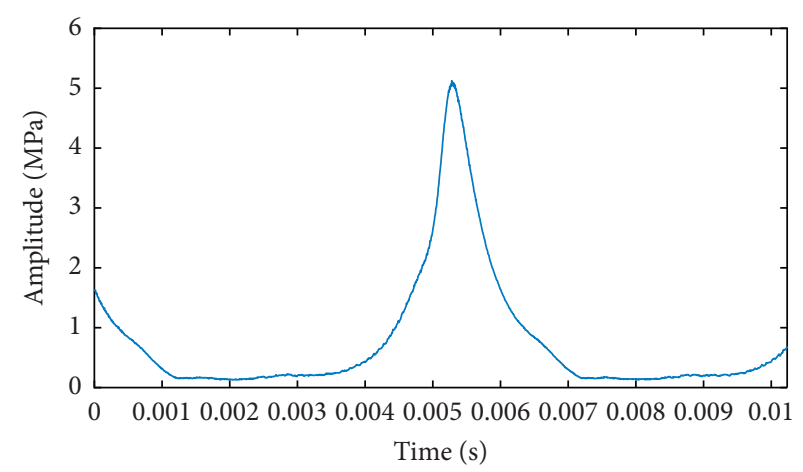

(a)

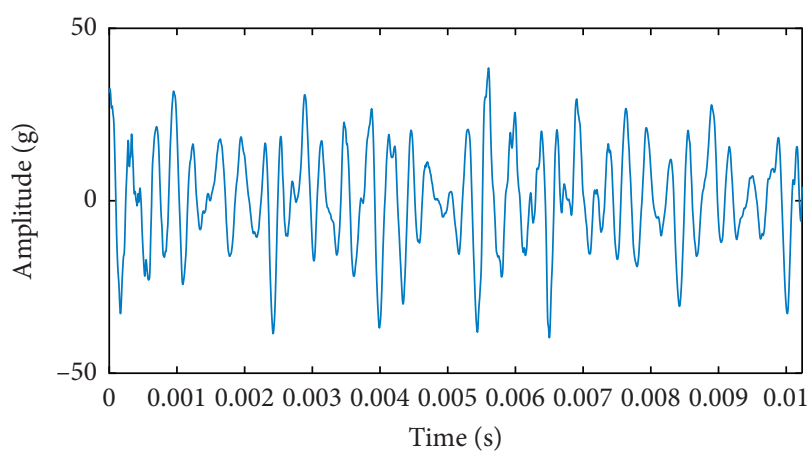

(b)

Figure 14: Time-domain diagram of the cylinder pressure signal and the engine vibration signal collected synchronously at $5000 \mathrm{rpm}$ when the ignition advance angle is $27^{\circ} \mathrm{CA}$. (a) Time-domain diagram of the cylinder pressure signal. (b) Time-domain diagram of the engine vibration signal.

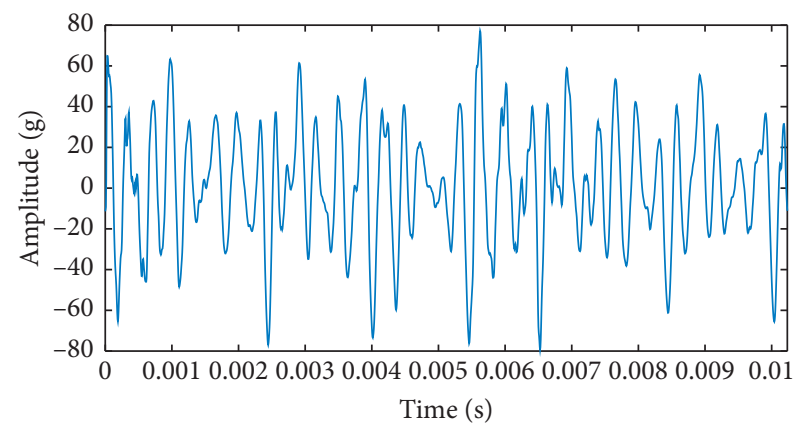

FIgURE 15: Time-domain diagram of the low-frequency signal component of the engine vibration signal at $5000 \mathrm{rpm}$ when the ignition advance angle is $27^{\circ} \mathrm{CA}$.

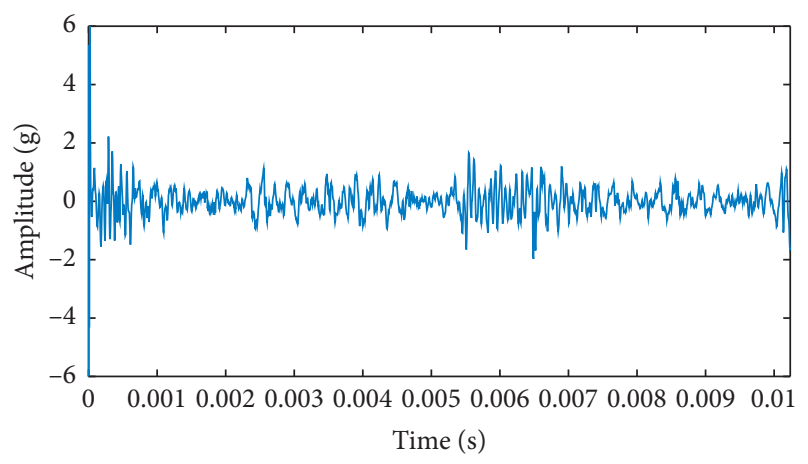

FIGURE 16: Time-domain diagram of the high-frequency noise signal component at $5000 \mathrm{rpm}$ when the ignition advance angle is $27^{\circ} \mathrm{CA}$.

The low-frequency signal component shown in Figure 15 was analyzed by FFT, and the frequency-domain figure was obtained as shown in Figure 17. As can be seen in Figure 17, the characteristic frequency of the engine is $3125 \mathrm{~Hz}$ when the ignition advance angle is $27^{\circ} \mathrm{CA}$ at $5000 \mathrm{rpm}$.

5.3. Verification of Algorithm. To verify the validity of the Mallat decomposition algorithm, wavelet packet energy method was used to extract the characteristic domain signal

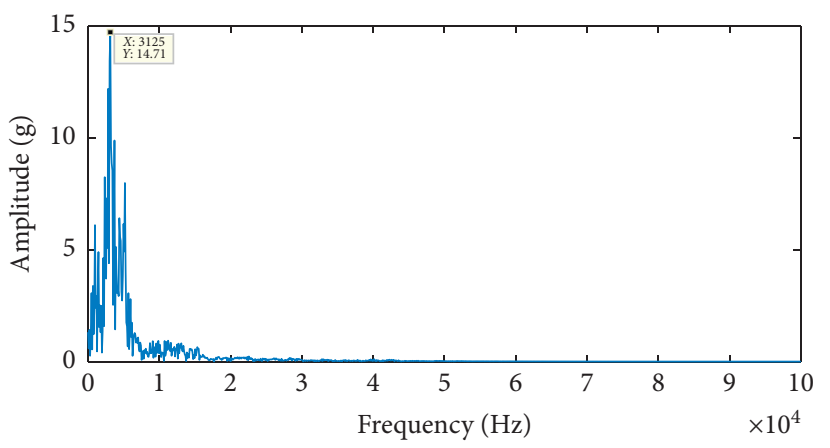

FIGURE 17: Frequency-domain diagram of the low-frequency signal component at $5000 \mathrm{rpm}$ when the ignition advance angle is $27^{\circ} \mathrm{CA}$.

from the engine vibration signal. The engine vibration signal in Figures 10(b) and 14(b) was decomposed to obtain 8 signal components, respectively, as shown in Figure 18.

The energy percentages of 8 signal components in Figures 18(a) and 18(b) were calculated, respectively, and the results are shown in Figure 19.

As can be seen from Figures 19(a) and 19(b), $S(3,0)$ and $S^{\prime}(3,0)$ have the largest energy percentage and are taken as the characteristic signal components. Using FFT to conduct analysis of $S(3,0)$ and $S^{\prime}(3,0)$, frequency-domain diagrams are obtained as shown in Figure 20.

It can be seen from Figures 20(a) and 20(b) that the characteristic frequencies of engine vibration signals at the ignition advance angle of $25^{\circ} \mathrm{CA}$ and $27^{\circ} \mathrm{CA}$ are $3027 \mathrm{~Hz}$ and $3125 \mathrm{~Hz}$, respectively, which are consistent with the characteristic frequencies in Figures 13 and 17. So, it can be proved that Mallat decomposition algorithm is correct to extract the knock characteristic domain signal.

5.4. Calculation of Knock Intensity. The characteristic domain signals obtained by the Mallat decomposition algorithm at the ignition advance angle of $25^{\circ} \mathrm{CA}$ and $27^{\circ} \mathrm{CA}$ are shown in Figures 11 and 15, respectively. By means of the characteristic domain signal, the knock intensity can be calculated by using the relative energy parameter. 


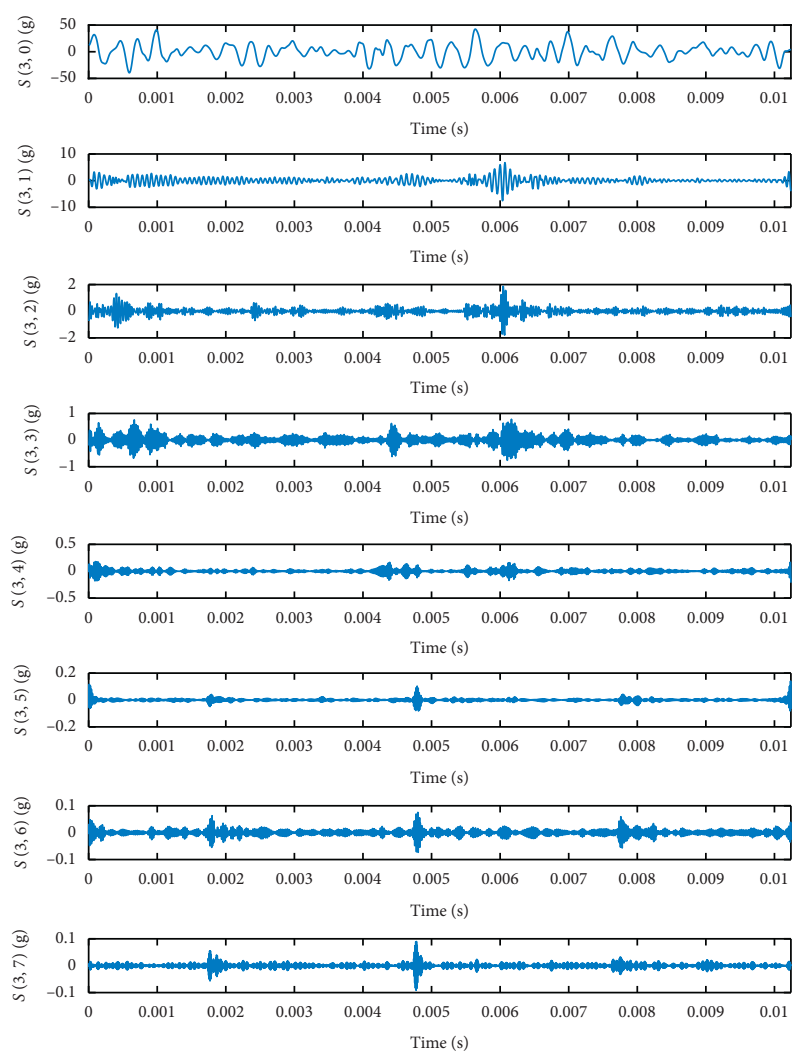

(a)
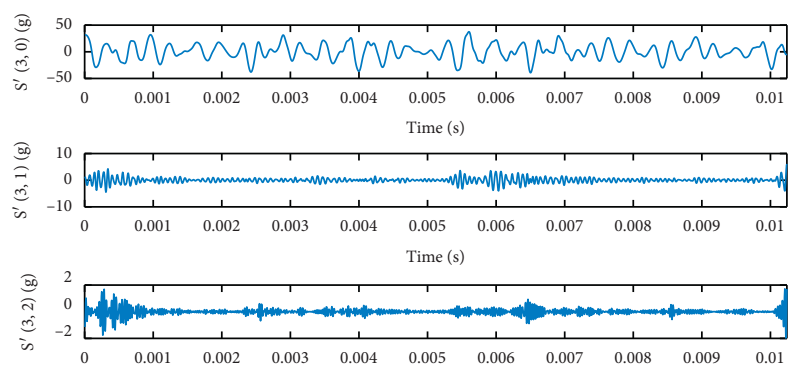

Time (s)
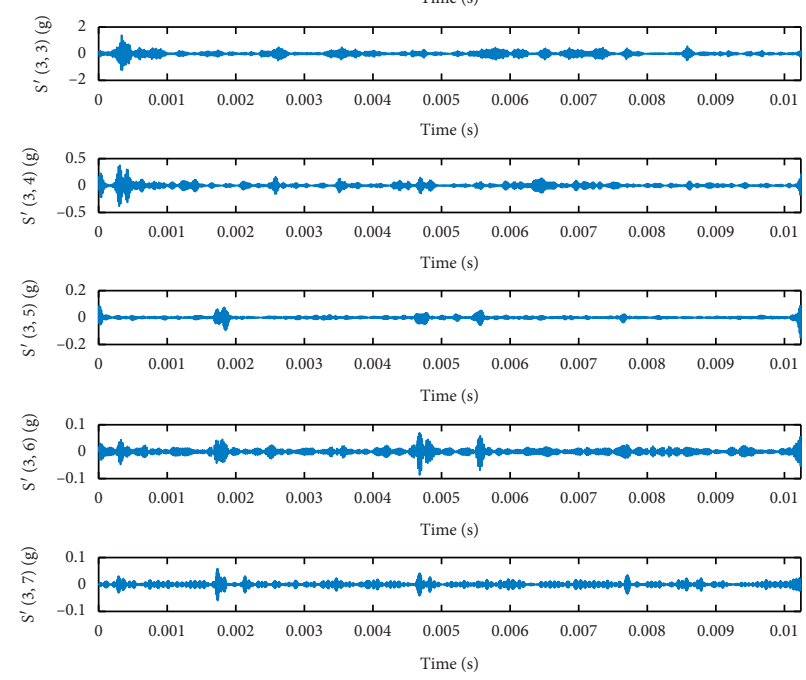

(b)

FIGURE 18: Eight signal components are obtained by using the wavelet packet energy method. (a) Eight signal components are decomposed from the engine vibration signal at $5000 \mathrm{rpm}$ with an ignition advance angle of $25^{\circ} \mathrm{CA}$. (b) Eight signal components are decomposed from the engine vibration signal at $5000 \mathrm{rpm}$ with an ignition advance angle of $27^{\circ} \mathrm{CA}$.

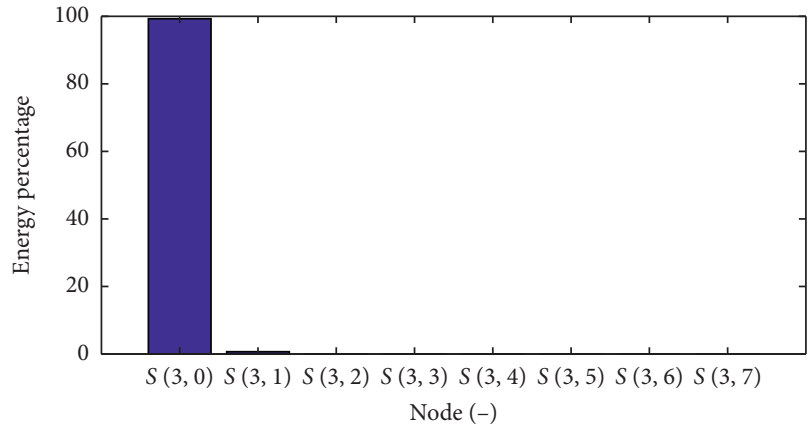

(a)

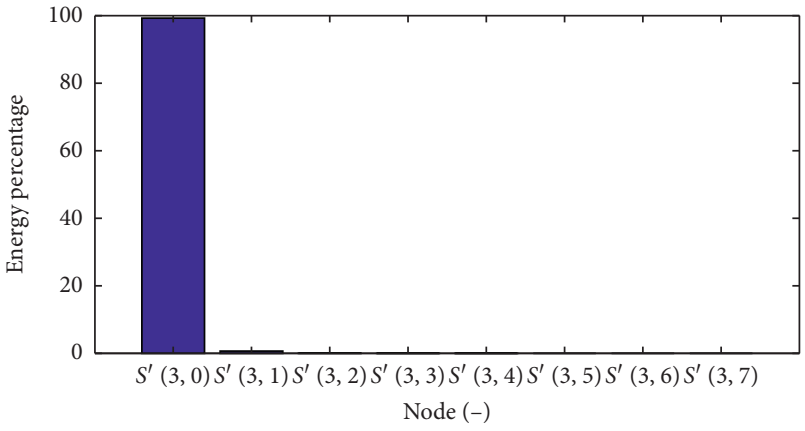

(b)

Figure 19: The energy percentage of 8 signal components. (a) The energy percentage of the 8 signal components obtained from the decomposition of the engine vibration signal at $5000 \mathrm{rpm}$ with an ignition advance angle of $25^{\circ} \mathrm{CA}$. (b) The energy percentage of the 8 signal components obtained from the decomposition of the engine vibration signal at $5000 \mathrm{rpm}$ with an ignition advance angle of $27^{\circ} \mathrm{CA}$.

The relative energy parameter [24] $E_{R}$ is defined as the ratio between the characteristic domain subband signal energy $E_{d}$ and the original signal energy (engine vibration signal) $E_{a}$. Its expression is

$$
E_{R}=\frac{E_{d}}{E_{a}}=\frac{\sum_{i=1}^{n} x_{i}^{2}}{\sum_{i=1}^{n} a_{i}^{2}}
$$

where $a_{i}$ is the engine vibration signal, $x_{i}$ is the characteristic domain signal, and $n$ is the number of points of the signal.

The knock intensity of the engine vibration signal in Figures 12 (b) and 14(b) is calculated by equation (19) as 3.9983 and 3.9973, respectively.

Mallat decomposition algorithm can obtain the characteristic domain signal components of engine vibration 


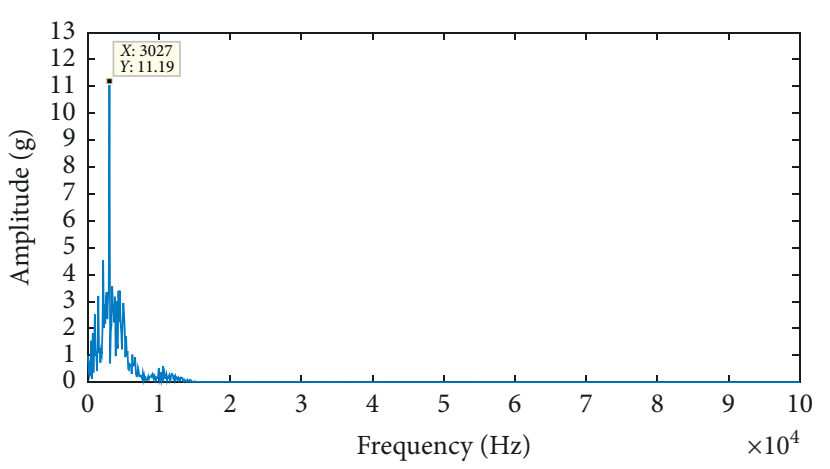

(a)

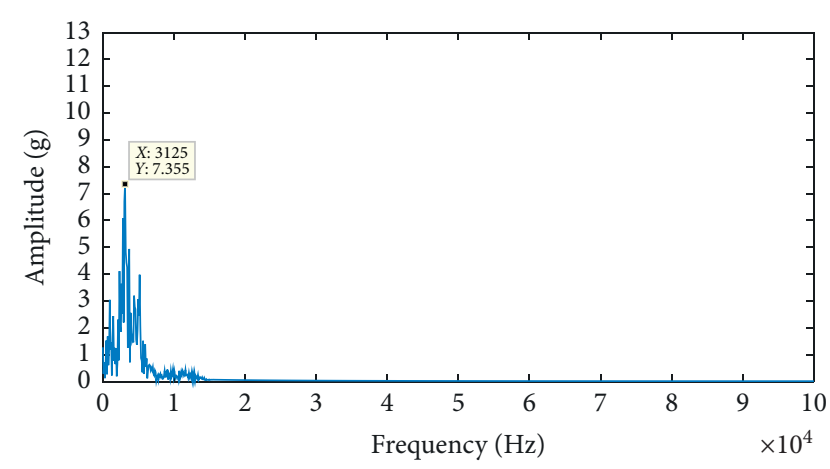

(b)

Figure 20: Frequency-domain diagrams of $S(3,0)$ and $S^{\prime}(3,0)$. (a) The frequency-domain diagram of $S(3,0)$. (b) The frequency-domain diagram of $S^{\prime}(3,0)$.

signal in the weak knock state. This component can be used to calculate the relative energy parameters, which can be used to describe the knock intensity and lay a foundation for the control of weak knock.

\section{Conclusion}

Mallat decomposition algorithm was used to separate the engine vibration signal, and the knock characteristic domain signal component was obtained. Wavelet packet energy method was used to verify the results. The knock characteristic domain signal component can be used to calculate the relative energy parameters of knock, which can provide the basis for knock control. In summary, Mallat decomposition algorithm can effectively extract the weak knock characteristics of engine vibration signals. This method is simple and efficient, which lays an important foundation for the weak knock control of two-stroke SI UAV engines.

\section{Data Availability}

The data used to support the findings of this study are available from the corresponding author upon request.

\section{Conflicts of Interest}

The authors declare no conflicts of interest.

\section{Acknowledgments}

This work was supported by the Science and Technology Research Project of Jiangxi Education Department (Grant no. GJJ201911), the National Natural Science Foundation of China (Grant no. 51865031), the Science and Technology Research Project of the Open Projects of Jiangxi Provincial Key Laboratory of Precision Drive and Control (Grant no. PLPDC-KFKT-201620), the Science and Technology Research Project of Jiangxi Education Department (Grant no. GJJ170989), the National Natural Science Foundation of China (Grant no. 51665020), and the Key Research and Development Project of Jiangxi Province (Grant no. 20192BBEL50015).

\section{References}

[1] T. Donateo, L. Spedicato, G. Trullo, A. P. Carlucci, and A. Ficarella, "Sizing and simulation of a piston-prop UAV," Energy Procedia, vol. 82, pp. 119-124, 2015.

[2] T. Korakianitis, A. M. Namasivayam, and R. J. Crookes, "Natural-gas fueled spark-ignition (si) and compression-ignition (ci) engine performance and emissions," Progress in Energy and Combustion Science, vol. 37, no. 1, pp. 89-112, 2011.

[3] A. R. H. Witwit, A. Yasin, H. Gitano, and T. K. Yadav, "New model for knock factors optimization in internal combustion engine (si)," Advanced Materials Research, vol. 980, pp. 219-224, 2014.

[4] X. Han, A. Yao, C. Yao, and G. Jian, "Investigation of energy transformation and damage effect under severe knock of engines," Applied Energy, vol. 203, pp. 506-521, 2017.

[5] S. Merola, C. Tornatore, L. Marchitto, G. Valentino, and F. Corcione, "Experimental investigations of butanol-gasoline blends effects on the combustion process in a SI engine," International Journal of Energy and Environmental Engineering, vol. 3, no. 1, p. 6, 2012.

[6] Z. Wang, Y. Wang, and R. D. Reitz, "Pressure oscillation and chemical kinetics coupling during knock processes in gasoline engine combustion," Energy \& Fuels, vol. 26, no. 12, pp. 7107-7119, 2012.

[7] R. Liu, J. Sheng, J. Ma, G. Yang, X. Dong, and Y. Liang, "Knock combustion investigation on $a$ two-stroke spark ignition UAV engine burning RP-3 kerosene fuel," Aircraft Engineering and Aerospace Technology, vol. 91, no. 10, pp. 1278-1284, 2019.

[8] A. Fahmi, F. Amin, and S. Niaz, "Decision making based on linguistic interval-valued intuitionistic neutrosophic Dombi fuzzy hybrid weighted geometric operator," Soft Computing, vol. 2020, 2020.

[9] H. Zhao, S. Zuo, M. Hou et al., "A novel adaptive signal processing method based on enhanced empirical wavelet transform technology," Sensors, vol. 18, no. 10, p. 3323, 2018.

[10] W. Deng, "Differential evolution algorithm with wavelet basis function and optimal mutation strategy for complex optimization problem," Applied Soft Computing, vol. 2020, 2020.

[11] W. Deng and J. Xu, "An enhanced MSIQDE algorithm with novel multiple strategies for global optimization problems," IEEE Transactions on Systems, Man, and Cybernetics: Systems, vol. 2020, 2020. 
[12] W. Deng, H. Liu, J. Xu, H. Zhao, and Y. Song, "An improved quantum-inspired differential evolution algorithm for deep belief network," IEEE Transactions on Instrumentation and Measurement, vol. 69, no. 10, pp. 7319-7327, 2020.

[13] B. Samimy and G. Rizzoni, "Mechanical signature analysis using time-frequency signal processing: application to internal combustion engine knock detection," Proceedings of the IEEE, vol. 84, no. 9, pp. 1330-1343, 1996.

[14] K. Akimoto, H. Komatsu, and A. Kurauchi, "Development of pattern recognition knock detection system using short-time fourier transform," IFAC Proceedings Volumes, vol. 46, no. 21, pp. 366-371, 2013.

[15] J. Chang, M. Kim, and K. Min, "Detection of misfire and knock in spark ignition engines by wavelet transform of engine block vibration signals," Measurement Science and Technology, vol. 13, no. 7, p. 1108, 2002.

[16] Z. Zhang and E. Tomita, "Knocking detection using wavelet instantaneous correlation method," JSAE Review, vol. 23, no. 4, pp. 443-449, 2002.

[17] D. Siano and D. D'Agostino, "Knock detection in si engines by using the discrete wavelet transform of the engine block vibrational signals," Energy Procedia, vol. 81, pp. 673-688, 2015.

[18] Z. Hou, C. Wang, and A. Yang, "Study on symmetric extension methods in mallat algorithm of finite length signal," 2008.

[19] L. Xue-fang and P. Tao, "Mallat algorithm of wavelet for timevarying system parametric identification," 2013.

[20] X. Zhang and W. Li, "The construction and the Mallat algorithm of biorthogonal two dimensional four-direction multi-wavelet with dilation factor a," Pure Mathematics, vol. 9, no. 9, pp. 1015-1035, 2019.

[21] S. G. Mallat, "A theory for multiresolution signal decomposition: the wavelet representation," IEEE Transactions on Pattern Analysis and Machine Intelligence, vol. 11, no. 7, pp. 674-693, 1989.

[22] G. Brecq and O. Corre, "Modeling of in-cylinder pressure oscillations under knocking conditions: introduction to pressure envelope curve," SAE Technical Papers, vol. 2005, 2005.

[23] J. Sheng, R. Liu, and G. Liu, "Weak knock characteristic extraction of a two-stroke spark ignition UAV engine burning RP-3 kerosene fuel based on intrinsic modal functions energy method," Sensors, vol. 20, no. 4, p. 1148, 2020.

[24] Y. Wang, Research on Knock Diagnosis and Control Strategy of Gasoline Engine, Harbin Institute of Technology, Harbin, China, 2010. 